\title{
Avaliação da adição de cinzas do bagaço de cana-de-açúcar em argamassas mistas
}

\author{
Evaluation of the addition of sugarcane bagasse ashes in \\ mixed mortars
}

\section{Tainara Rigotti de Castro Carlos Humberto Martins}

\section{Resumo}

$\mathbf{E}$

ste trabalho apresenta uma análise do efeito da adição de cinzas do bagaço de cana-de-açúcar (SCBA) em argamassas mistas adotando-se o traço, em volume, 1:2:9 (cimento:cal:agregado miúdo). As cinzas foram caracterizadas em relação à distribuição de partículas, à atividade pozolânica, à composição química, à massa específica, ao teor de umidade e ao teor de perda ao fogo. Posteriormente, foram produzidas argamassas com relação água-cimento constante $(2,64)$, com substituição parcial de agregado miúdo pela cinza pesada do bagaço de cana-de-açúcar, com diferentes teores de substituição $(0 \%, 5 \%, 10 \%, 15 \%$ e $20 \%)$, em massa. Entre estes foi selecionado um traço, tendo em vista que suas características não passaram a ter desvantagens significativas, a fim de fazer a substituição de 7,5\% de cimento por cinza leve do bagaço de cana-de-açúcar. As argamassas foram caracterizadas no estado fresco quanto a retenção de água, densidade de massa e teor de ar incorporado, e no estado endurecido quanto a coeficiente de capilaridade, resistência à tração na flexão e compressão axial e módulos de elasticidade longitudinal e flexional. A análise dos resultados mostrou que as cinzas podem ser incorporadas às argamassas sem que estas sofram significativas alterações em suas propriedades.

Palavras-chaves: Cinza leve. Cinza pesada. Argamassa. Substituição parcial. Bagaço de cana-de-açúcar.

Tainara Rigotti de Castro Universidade Estadual do Paraná Campo Mourão - PR - Brasil

Carlos Humberto Martins Universidade Estadual de Maringá Maringa - PR - Brasil

Recebido em 15/06/15 Aceito em 10/03/16

\section{Abstract}

The aim of this paper is to analyze the effect of addition of sugarcane bagasse ashes (SCBA) in mixed mortars utilizing a 1:2:9 mix proportion by volume for cement, lime and fine aggregate. The ashes were characterized by its particle distribution, pozzolanic activity, chemical composition, bulk density, moisture content and loss on ignition. Then the mortars were produced with a constant water/cement ratio of 2.64 and a partial replacement of sand with sugarcane bagasse heavy ash using different substitution percentages $(0 \%, 5 \%, 10 \%, 15 \%$ and 20\%). Among these was selected a trace, considering that its features have not undergone significant downsides to the $7.5 \%$ replacement of cement by fly ash. The mortars were characterized in the plastic state: water retention, bulk density and air content, and in the hardened state: capillary coefficient, tensile strength by bending test, axial compressive strength and flexural and longitudinal Young's modulus. Thus results analysis showed that the ashes can be incorporated into mortars without causing significant alterations in its properties.

Keywords: Fly ash. Heavy ash. Mortars. Partial replacement. Bagasse cane.

CASTRO, T. R. de; MARTINS, C. H.Avaliação da adição de cinzas do bagaço de cana-de-açúcar em argamassas mistas. 137 Ambiente Construído, Porto Alegre,v. 16, n. 3,p. 137-151, jul./set. 2016. ISSN 1678-8621 Associação Nacional de Tecnologia do Ambiente Construído. http://dx.doi.org/10.1590/s1678-86212016000300097 


\section{Introdução}

A indústria da construção é indiscutivelmente essencial para o crescimento de uma nação, por desempenhar um papel vital para sociedade, ao transformar necessidades em infraestrutura (IBRAHIM et al., 2010). Todavia, o atendimento dessas necessidades tem consumido desenfreadamente recursos naturais da Terra, mediante a fabricação de um enorme volume de materiais. A areia e o cimento são muito empregados na construção civil, sendo suas matérias-primas extraídas do solo por meio da mineração. Brown e Lugo (1994) destacam que as extrações dessas matérias-primas geralmente vêm acompanhadas de impactos ambientais, seguidos da degradação do meio ambiente. As áreas degradadas, por definição, não possuem mais capacidade de repor as perdas de matéria orgânica do solo - nutrientes, biomassa e estoque de propágulos -, que fica com as características biológicas, físicas e químicas alteradas, a ponto de tornar o solo estéril.

Além de provocar a extração de calcário do solo, a produção de cimento consome muita energia e emite grande quantidade de dióxido de carbono na atmosfera. Por isso, a redução da utilização tanto da areia como do cimento é considerada muito importante para combater os problemas de degradação e a poluição do meio ambiente.

A melhor maneira de diminuir a utilização desses recursos e conservar o meio ambiente é o emprego de formas alternativas, entre as quais está o uso de resíduos industriais como matéria-prima (ALWAELI, 2013). Sob essa óptica, além da redução da demanda da extração de recursos naturais, ainda há a possibilidade de obtenção de produtos com propriedades superiores.

No entanto, a grande quantidade de resíduos industriais produzidos em todo o mundo implica que, atualmente, sua reciclagem seja extremamente necessária, não só devido ao aumento do custo de sua deposição em aterros, que reflete no custo dos produtos, mas também como uma consequência da busca pelo desperdício zero, que deve ser o objetivo final de todas as futuras atividades humanas (FARAONE et al., 2009).

A incorporação de resíduos no emprego de formas alternativas tem mostrado resultados satisfatórios na literatura, principalmente na utilização de cinzas do bagaço de cana-de-açúcar no ramo da construção civil (GONZÁLEZ-LÓPEZ et al., 2015; CHEN et al., 2013; LIMA et al., 2012; SOUZA et al., 2011; AKRAM; MEMON; OBAID, 2009; CORDEIRO et al., 2009).As pesquisas reúnem a caracterização das cinzas utilizadas, bem como as aplicações desse resíduo na área da construção civil, após adições e substituições parciais de agregados e aglomerantes, tanto em concretos, pastas de cimento e argamassas quanto em materiais cerâmicos.

No processo de beneficiamento da cana-de-açúcar o maior subproduto gerado é o bagaço dela, utilizado em larga escala como combustível em caldeiras, cujos resultados são geração de energia e cinzas. Como na safra 2013/2014 a colheita foi de 652 milhões de toneladas de cana-de-açúcar, considerando-se que se utilizou todo o bagaço como fonte de energia, foram então gerados aproximadamente 3,9 milhões de toneladas de cinza (COMPANHIA..., 2013).

Parte da cinza gerada, dita cinza pesada, é depositada num cinzeiro abaixo da grelha da caldeira, e o restante, de distribuição granulométrica mais fina, dita cinza volante ou leve, é suspensa pelos gases de combustão e, antes de ser dispersa na atmosfera através da chaminé, passa por algum processo de limpeza de gases, para redução nas emissões de particulados. Salienta-se que o processo de separação dessas cinzas difere de acordo com a tecnologia utilizada pela indústria.

Parte dessas cinzas, juntamente com torta de filtro e vinhaça, volta para o solo dos canaviais para ser utilizada como adubo, apesar de ser um componente pobre em nutrientes e de difícil deterioração, e de possuir em sua composição metais pesados,que podem contaminar o solo e os lençóis freáticos. A literatura ressalta que essa prática é comum entre os agricultores de cana, chamada de iniciativa ambientalmente correta, porém ignora o uso de agrotóxicos nas plantações, que persistem no solo com as cinzas (SALES; LIMA, 2010). Assim, as cinzas, quando descartadas de maneira inadequada, podem causar a contaminação dos solos adjacentes edas águas subterrâneas e causar problemas de saúde, trazendo graves problemas sociais e ambientais. Por isso, não havendo outro modo de utilização, o correto é que esse resíduo, classificado como inerte, seja destinado aos aterros sanitários (FRÍAS; VILLAR; SAVASTANO, 2011).

Devido à necessidade de diminuir a deposição desse resíduo, bem como de diminuir a utilização de materiais como areia e cimento e os consequentes impactos ambientais causados por sua extração, esta pesquisa analisou os efeitos da adição de cinzas do bagaço de cana-de-açúcar da região Sul do Brasil em argamassas mistas com o traço 1:2:9 (cimento:cal:agregado miúdo, em 
volume). Primeiramente, foi utilizada a substituição parcial do agregado miúdo pela cinza pesada do bagaço de cana-de-açúcar em cinco formulações de traço, e entre as substituições em massa realizadas foi selecionado um traço,para a realização da substituição de $7,5 \%$ em massa de cimento pela cinza leve do bagaço de cana-deaçúcar. Além disso, os dois tipos de cinza foram analisados, a fim de se conhecerem suas características físicas e químicas.

\section{Metodologia}

\section{Materiais}

Para a produção das argamassas mistas foram utilizados cimento, cal, agregado miúdo, cinza pesada e cinza leve do bagaço de cana-de-açúcar e água de amassamento. $\mathrm{O}$ cimento foi do tipo Portlandcomposto, classe 32 (CP II Z - 32), fabricado no Paraná, Brasil. Possui massa específica de $2,97 \mathrm{~g} / \mathrm{cm}^{3}$, tempo de início e fim de pega de 290 h:min e 363 h:min respectivamente, e área de superfície específica Blaine de 3.526 $\mathrm{cm}^{2} / \mathrm{g}$. A cal foi a hidratada $\mathrm{CH}$ III da marca Mottical, proveniente do Paraná, com massa específica de 2,60 $\mathrm{g} / \mathrm{cm}^{3}$ e área de superfície específica Blaine de $1.314 \mathrm{~cm}^{2} / \mathrm{g}$. A areia utilizada como agregado miúdo é proveniente da região de Maringá, PR.

As cinzas utilizadas no estudo foram obtidas a partir de uma usina de açúcar localizada no Sul do Brasil. Foram coletadas em um fundo de caldeira (cinza pesada) e de um equipamento retentor de fuligem via úmida (cinza leve). Essas amostras são aqui referidas como SCBA1 e SCBA2 respectivamente. As cinzas foram colocadas em sacos plásticos, para posterior caracterização. A SCBA1, antes dos procedimentos, foi peneirada em malha 0,6 para a retirada de folhas e pedaços de bagaço com queima incompleta. A SCB2 foi seca em temperatura ambiente por $48 \mathrm{~h}$ e continuou secando em estufa a $100{ }^{\circ} \mathrm{C}$ por mais $48 \mathrm{~h}$ para a retirada de umidade. Após a etapa de secagem, o material foi desgrumado.

Neste projeto experimental se fixou a formulação da argamassa, em volume, em 1:2:9 (cimento:cal:agregado miúdo). A fim de garantir a mesma proporção dos materiais empregados na produção das argamassas, o traço em volume foi convertido para o traço em massa (Equação 1).

$$
1:\left(\mathrm{V}_{\mathrm{p}} \times \delta_{\mathrm{p}}\right) / \delta_{\mathrm{c}}:\left(\mathrm{V}_{\mathrm{q}} \times \delta_{\mathrm{q}}\right) / \delta_{\mathrm{c}} \quad \text { Eq. } 1
$$

$\mathrm{V}_{\mathrm{p}}$ é a proporção de cal hidratada no traço da argamassa em volume aparente;

$\mathrm{V}_{\mathrm{q}}$ é a proporção do agregado miúdo no traço da argamassa em volume aparente;

$\delta_{\mathrm{p}}$ é a massa unitária da cal, no estado solto, em $\mathrm{kg} / \mathrm{dm}^{3}$;

$\delta_{\mathrm{q}}$ é a massa unitária do agregado miúdo, no estado seco, em kg/dm³; e

$\delta_{c}$ é a massa unitária do cimento, no estado solto, $\mathrm{em} \mathrm{kg} / \mathrm{dm}^{3}$.

Com as proporções obtidas em massa $(\mathrm{kg})$, foi fixada a quantidade de $2,5 \mathrm{~kg}$ de materiais secos para cada mistura, conforme recomendado na NBR 13276(ABNT, 2005a), a partir do que o agregado miúdo foi substituído pela SCBA1 (Tabela 1).

A quantidade de água utilizada foi a necessária para se obter um índice de consistência de $260 \pm 5$ $\mathrm{mm}$, de acordo com a NBR 13276(ABNT, 2005a), remetendo a uma relação água-cimento de 2,64. Os espalhamentos obtidos estão dispostos na Tabela 2. O acréscimo de SCBA1 causou diminuição da consistência das argamassas, provavelmente pelo fato de essa amostra possuir alta superfície específica. Dessa forma, fez-se a adição do aditivo superplastificanteSikaViscocrete 20HE, que também foi utilizado por Macedo (2009) na confecção de argamassas com adição de cinza do bagaço de cana-de-açúcar. A dosagem recomendada pelo fabricantepara argamassas, de $0,2 \%$ a $0,9 \%$ sobre o peso de cimento, foi a adotada, para melhorar a trabalhabilidade dos traços M3 e M4, visto que estes possuíram consistência menor do que a empregada.

Após a caracterização das argamassas de acordo com a composição da Tabela 1, um traço foi selecionado. Como nenhum dos traços consegue ser o melhor em todas as propriedades analisadas, o parâmetro de escolha utilizado foi a comparação da resistência do traço selecionado com o de referência (M0), levando-se em consideração que a avaliação dessa propriedade envolve a análise de várias outras.

Após a seleção do traço, realizou-se a substituiçãoparcial de $7,5 \%$ de cimento por SBCA2, para posterior caracterização. Essa proporção foi escolhida pelo fato de Hojo (2014) ter chegado à conclusão de que substituições até essa proporção remetem a resistências semelhantes ao traço sem substituição, o que reduz o consumo de cimento.

Onde: 
Tabela 1 - Composição do traço para 2,5 kg de materiais secos

\begin{tabular}{|c|c|c|c|c|c|c|c|}
\hline \multirow[b]{2}{*}{ Argamassas } & \multirow{2}{*}{$\begin{array}{c}\text { Teor de } \\
\text { substituição } \\
\text { em massa } \\
(\%)\end{array}$} & \multicolumn{6}{|c|}{ Materiais } \\
\hline & & $\begin{array}{l}\text { Cimento } \\
\text { (g) }\end{array}$ & Cal (g) & Areia (g) & $\underset{\text { (g) }}{\operatorname{SCBA1}}$ & $\begin{array}{c}\text { Água } \\
\text { (ml) }\end{array}$ & $\begin{array}{c}\text { Superplastifi- } \\
\text { cante (ml) }\end{array}$ \\
\hline M0 & 0 & 176 & 217 & 2.107 & 0 & 365 & 0 \\
\hline M1 & 5 & 176 & 217 & 2.002 & 105 & 365 & 0 \\
\hline M2 & 10 & 176 & 217 & 1.896 & 211 & 365 & 0 \\
\hline M3 & 15 & 176 & 217 & 1.791 & 316 & 365 & 0,2 \\
\hline M4 & 20 & 176 & 217 & 1.686 & 421 & 365 & 0,2 \\
\hline
\end{tabular}

Tabela 2 - Espalhamento das argamassas

\begin{tabular}{cc}
\hline Argamassas & Espalhamento $(\mathbf{m m})$ \\
\hline M0 & 264 \\
M1 & 260 \\
M2 & 256 \\
M3 & 265 \\
M4 & 264 \\
\hline
\end{tabular}

\section{Fabricação de argamassas}

A mistura dos materiais foi realizada com o auxílio de um misturador de bancada laboratorial. A ordem de mistura foi a sequência água no pó, conforme a NBR 13276 (ABNT, 2005a). Assim, foram misturados todos os componentes, exceto o cimento, em velocidade baixa durante $4 \mathrm{~min}$. A mistura foi realizada com antecedência de $16 \mathrm{~h}$ a 24h, conforme especificado pela NBR 13276 (ABNT, 2005a), antes da execução dos ensaios ou moldagem dos corpos de prova, sendo registrada a pesagem da argamassa pronta. Após esse intervalo de maturação, a argamassa foi novamente pesada, acrescida do cimento e da quantidade de água correspondente a eventual perda de água por evaporação e misturada em velocidade baixa durante $4 \mathrm{~min}$.

\section{Métodos}

\section{Caracterização das cinzas}

A distribuição das partículas da SCBA1 e SCBA2 foi determinada pela combinação dos procedimentos de peneiramento e sedimentação sugeridos pela NBR 7181 (ABNT, 1984b). A atividade pozolânica foi determinada através do Método de Chapelle modificado pela NBR 15895 (ABNT, 2010). Pela NBR 6508 (ABNT, 1984a), foi determinada a massa específica de cada amostra de cinza. Determinou-se o teor de umidade mediante a secagem das amostras de resíduos em estufa por $24 \mathrm{~h}$ a $100{ }^{\circ} \mathrm{C}$, conforme especificações da NBR NM 24 (ABNT, 2003), e o teor de perda ao fogo foi determinado conforme a NBR NM 18 (ABNT, 2012), mediante a calcinação das amostras em forno mufla à temperatura de $950 \pm 50{ }^{\circ} \mathrm{C}$ por no mínimo $50 \mathrm{~min}$ A composição química das amostras foi determinada utilizando-se espectrômetro de raios $\mathrm{X}$ Rigaku, com radiação $\mathrm{Pd} \mathrm{K \alpha}$, corrente de 1,2 mA e voltagem de $40 \mathrm{kV}$. Os contaminantes presentes nas cinzas foram analisados por meio da obtenção do extrato lixiviado, seguindo especificações da NBR 10005 (ABNT, 2004b), e solubilizado, de acordo com a NBR 10006 (ABNT, 2004c), para a determinação dos teores de contaminantes constantes na NBR 10004 (ABNT, 2004a), por meio de espectrômetro de absorção atômica (EAA 52 VarianSpectrAA 240FS) e cromatógrafo de íons (Metrohm 850 Professional IC).

\section{Caracterização das argamassas}

Para a caracterização das argamassas foram realizados procedimentos no estado fresco e no estado endurecido.

No estado fresco as argamassas foram caracterizadas em relação à retenção de água, de acordo com a NBR 13277 (ABNT, 2005b), e densidade de massa e teor de ar incorporado, segundo a NBR 13278 (ABNT, 2005c).

No estado endurecido foi realizada a determinação do coeficiente de capilaridade, conforme recomendações da NBR 15259 (ABNT, 2005e), utilizando corpos de prova prismáticos com dimensões 40x40x160 mm, moldados de acordo com a NBR 13279 (ABNT, 2005d). Suas massas foram registradas, com uma de suas faces em contato com água, aos 10min e aos 90min. A resistência mecânica das peças foi determinada através da tração à flexão (ABNT, 2005d), em 15 corpos de prova, com a aplicação de uma carga distribuída uniformemente na seção transversal no

140 Castro, T. R. de; Martins, C. H. 
meio do corpo de prova prismático biapoiado (Figuras 1a e 1b). Com a utilização das metades dos corpos de prova rompidos, testou-se a compressão axial de 20 peças (Figuras 1c e 1d). Determinou-se o módulo de elasticidade conforme a norma americana ASTM E 1876 - 09 (AMERICAN..., 2012), em 15 corpos de prova, através da utilização de uma técnica de excitação por impulso determinada pelas condições de contorno em modo longitudinal E long (Figura 2a) e modo flexional $E$ flex (Figura 2b). Para isso, foram utilizados corpos de prova cilíndricos com 5 $\mathrm{cm}$ de diâmetro e $10 \mathrm{~cm}$ de altura, moldados de acordo com a NBR 7215 (ABNT, 1996).

Os parâmetros adotados para os experimentos no estado endurecido envolvem a produção das argamassas e cura dos corpos de prova sob condições laboratoriais com temperatura do ar a $23 \pm 2{ }^{\circ} \mathrm{Ce}$ umidade relativa do ar de $60 \pm 5^{\circ} \mathrm{C}$, com desmoldagem após $48 \mathrm{~h}$ da moldagem. Os ensaios foram desenvolvidos nos corpos de prova quando estes completaram 28 dias de idade.

\section{Figura 1 - Configurações de ensaios}

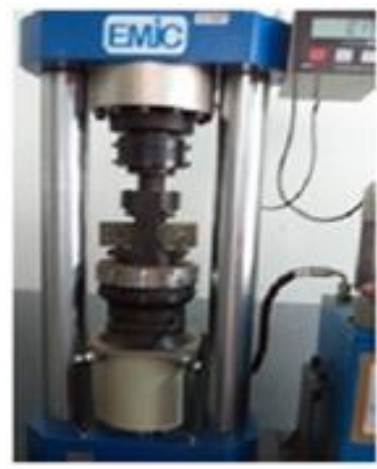

(a) Tração à flexão

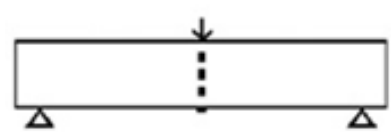

(b) Força aplicada na tração à flexão

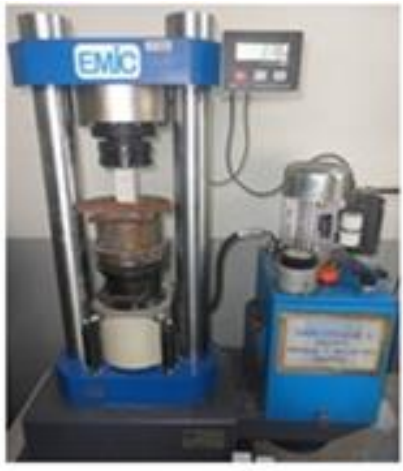

(c) Compressão axial
A análise estatística utilizada foi realizada por meio da Análise de Variância (ANOVA) e do teste de Tukey. Utilizou-se o software estatístico Statistica 8.0 para a realização do estudo.

A ANOVA foi utilizada para verificar se existia diferença entre as médias das composições ou tratamentos, com determinado limite de confiança (95\%), além de verificar a precisão das médias de cada composição ou tratamento (MONTGOMERY; RUNGER, 2013). Quando a ANOVA mostra que existem diferenças significativas entre as médias dos tratamentos, é necessário aplicar o teste de Tukey, utilizado para verificar quais médias são estatisticamente diferentes entre si ao nível de $5 \%$ de probabilidade. De acordo com o teste de Tukey, duas médias são diferentes entre si quando o valor absoluto da diferença entre eles for maior do que a diferença mínima significativa (d.m.s) calculada (BRITO, 2007).

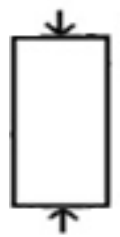

(d) Força aplicada na compressão

Axial

Figura 2 - Condições de contorno do modulo de elasticidade

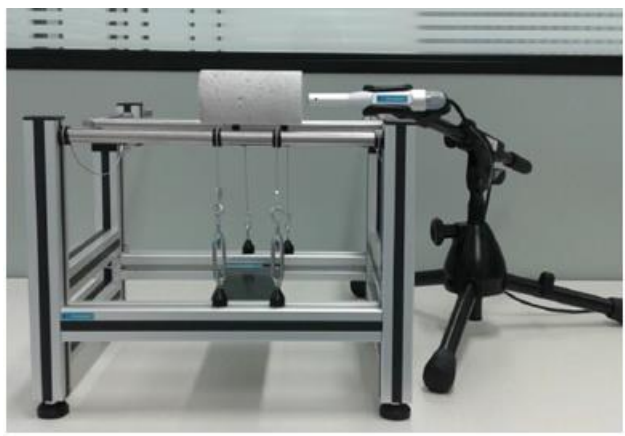

(a) Modo longitudinal E long

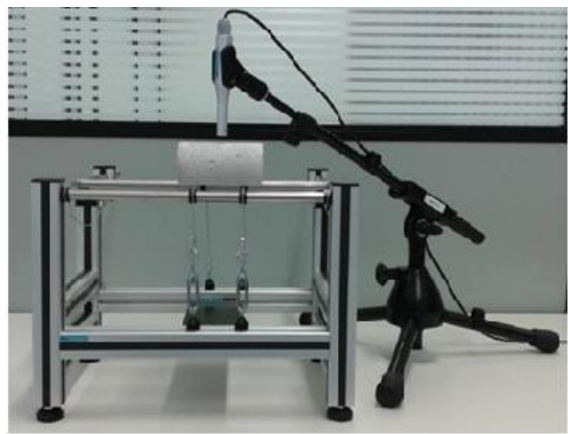

(b) Modo flexional E flex 


\section{Resultados e discussão}

\section{Caracterização das cinzas}

As curvas de distribuição de tamanho de partículas da SCBA1 e da SCBA2 são mostradas na Figura 3, juntamente com a curva granulométrica do agregado miúdo. Os resultados revelaram que $51 \%$ das cinzas da amostrade SCBA1 ficaram retidas nas peneiras de $0,06 \mathrm{~mm}$ a $0,2 \mathrm{~mm}$, o que, de acordo com a classificação da NBR 6502 (ABNT, 1995), as torna semelhantes à areia fina. A SCBA2 teve $81 \%$ da amostra retida, sendo então semelhante ao silte. As amostras de SCBA1 e SCBA2 mostraram pouca variação no diâmetro das partículas. A SCBA1 possui módulo de finura 2,98, e a SCBA2, 2,91. Em contrapartida, o agregado miúdo possui massa específica de 2,64 $\mathrm{g} / \mathrm{cm}^{3}$ e módulo de finura de 2,91.

O valor obtido na amostra de SCBA1 resultou em $101 \mathrm{mg} \mathrm{Ca}(\mathrm{OH})_{2 / \mathrm{g}}$ amostra, o que caracteriza que essa cinza não possui atividade pozolânica. $\mathrm{O}$ valor obtido para a SCBA2 foi de $569 \mathrm{mg} \mathrm{Ca}(\mathrm{OH})_{2 / \mathrm{g}}$ amostra, o que caracteriza pozolanicidade, podendo ser viável sua substituição por cimento.

Em relação à massa específica, foram encontrados valores semelhantes aos da areia $\left(2,64 \mathrm{~g} / \mathrm{cm}^{3}\right)$, sendo de $2,75 \mathrm{~g} / \mathrm{cm}^{3}$ para SCBA1 e de $2,64 \mathrm{~g} / \mathrm{cm}^{3}$ para SCBA2. Sales e Lima (2010) encontraram resultados semelhantes para cinzas coletadas em quatro usinas distintas, em que as massasespecíficas das amostras foram muito semelhantes à do agregado, próximo de 2,65 $\mathrm{g} / \mathrm{cm}^{3}$.

Mediante a determinação do teor de umidade pode-se constatar o quão a SBCA2 é mais úmida $(1,68 \%)$ em relação à $\operatorname{SBCA1}(0,16 \%)$.

O teor de perda ao fogo da SCBA1 e da SCBA2 foi de $9,56 \%$ e $13,92 \%$ respectivamente. Agredo et al. (2014)encontraram valores próximos aos desta pesquisa, de $10 \%$ para a cinza pesada e de $14 \%$ para a cinza leve. Essa propriedade está diretamente ligada à quantidade de matéria orgânica presente nesses resíduos.

As composições químicas das amostras de resíduos de cinzas são apresentadasna Tabela 3. De acordo com os referidos dados, a SCBA1 contém grande quantidade de sílica $(57,41 \%)$ e menor grau de óxido de ferro $(21,79 \%)$. Para a SCBA2 ocorre o inverso, maior presença de óxido de ferro $(47,98 \%)$ e menor grau de sílica $(25,82 \%)$. Quando comparadasà literatura, as cinzas desta pesquisa tendem a ter menor quantidade de sílica, tendo sido encontradona cinza pesada um teor de $66,61 \%$ de sílica (FRÍAS; VILLAR; SAVASTANO, 2011), e na cinza leve porcentagem de $61,59 \%$ (FARIA; GURGEL; HOLANDA, 2012) e 47,4\% (UYGUNOGLUet al., 2012). Esses resultados podem estar relacionados com as diferenças de solos onde a cana é cultivada, métodos de fertilização do solo e métodos de queima do bagaço, entre outros.

Figura 3 - Curvas de distribuição granulométrica das cinzas do bagaço de cana-de-açúcar e da areia

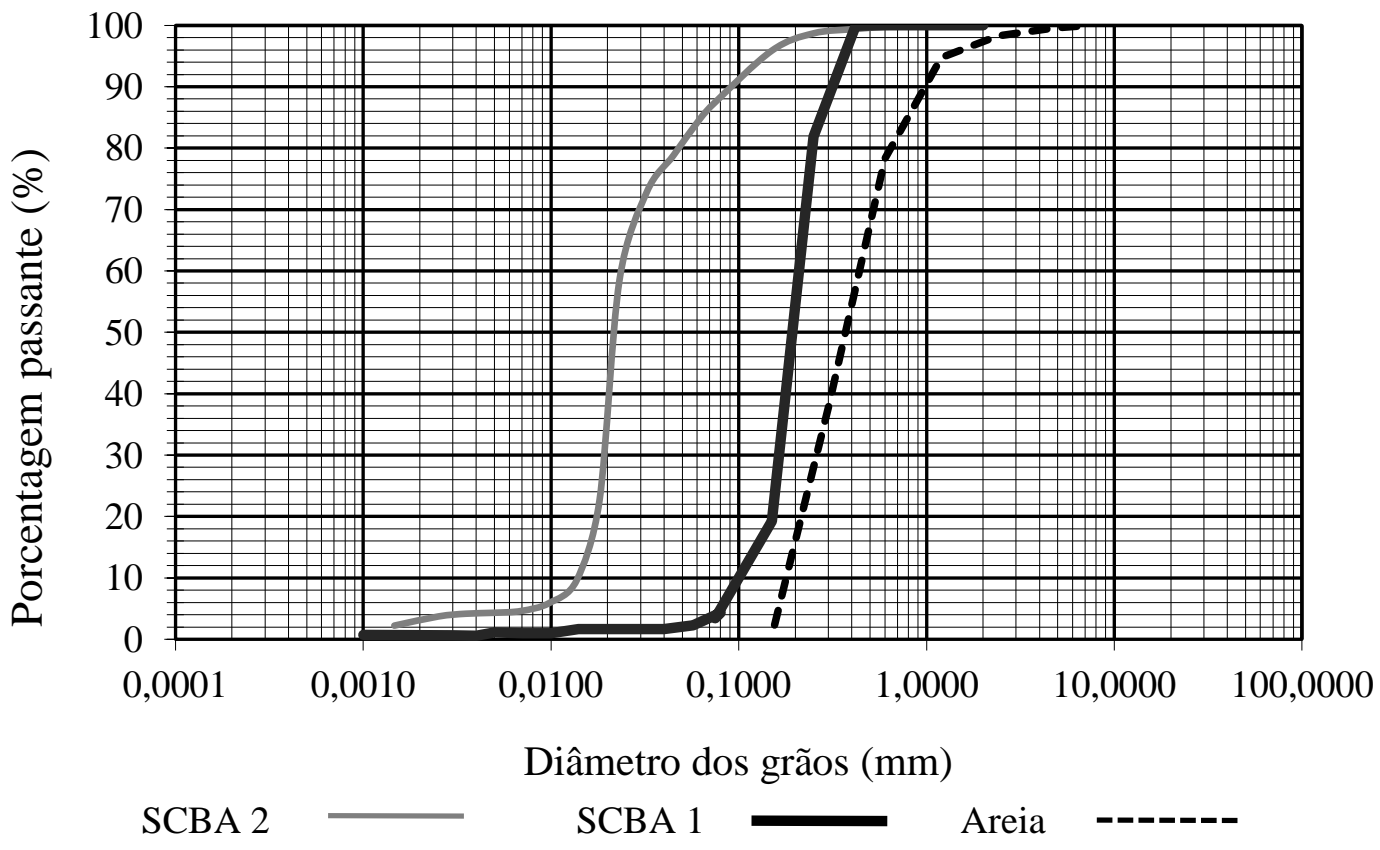

142 Castro, T. R. de; Martins, C. H. 
Tabela 3 - Composição química da SCBA1 e da SCBA2

\begin{tabular}{|c|c|c|c|}
\hline \multirow{2}{*}{ Elemento } & \multirow{2}{*}{$\begin{array}{c}\text { Fórmula } \\
\text { composta } \\
\end{array}$} & \multicolumn{2}{|c|}{ Concentração (\%) } \\
\hline & & SCBA1 & SCBA2 \\
\hline $\mathrm{Si}$ & $\mathrm{SiO}_{2}$ & 57,41 & 25,82 \\
\hline $\mathrm{Fe}$ & $\mathrm{Fe}_{2} \mathrm{O}_{3}$ & 21,79 & 47,98 \\
\hline $\mathrm{Ti}$ & $\mathrm{TiO}_{2}$ & 6,41 & 7,16 \\
\hline $\mathrm{Al}$ & $\mathrm{Al}_{2} \mathrm{O}_{3}$ & 4,31 & 10,57 \\
\hline K & $\mathrm{K}_{2} \mathrm{O}$ & 4,05 & 4,15 \\
\hline $\mathrm{Ca}$ & $\mathrm{CaO}$ & 1,96 & 1,53 \\
\hline $\mathrm{P}$ & $\mathrm{P}_{2} \mathrm{O}_{5}$ & 1,14 & 0,79 \\
\hline $\mathrm{Mg}$ & $\mathrm{MgO}$ & 1,03 & 0,68 \\
\hline $\mathrm{V}$ & $\mathrm{V}_{2} \mathrm{O}_{5}$ & 0,72 & - \\
\hline $\mathrm{Cl}$ & $\mathrm{Cl}$ & 0,46 & 0,19 \\
\hline $\mathrm{Mn}$ & $\mathrm{MnO}$ & 0,37 & 0,73 \\
\hline S & $\mathrm{SO}_{3}$ & 0,25 & - \\
\hline $\mathrm{Zr}$ & $\mathrm{ZrO}_{2}$ & 0,11 & 0,11 \\
\hline $\mathrm{Cu}$ & $\mathrm{CuO}$ & - & 0,16 \\
\hline $\mathrm{Zn}$ & $\mathrm{ZnO}$ & - & 0,13 \\
\hline
\end{tabular}

A Tabela 4 mostra que o teste de solubilização indicou a presença de metais pesados nas amostras de SCBA1 e de SCBA2. Os resultados do extrato de lixiviação ficaram dentro do limite permitido para o grupo de compostos orgânicos, de acordo com o Anexo F da NBR 10004 (ABNT, 2004a). O ensaio de solubilização revelou elementos químicos que excediam o nível permitido empregado pelo anexo $\mathrm{G}$ da referida norma. Portanto, as amostras de SCBA1 e de SCBA2 foram classificadas aqui como "resíduos não perigosos - classe II A - não inerte" (ABNT, 2004a), assim como cinzas já caracterizadas (SALES; LIMA, 2010).

\section{Caracterização das argamassas mistas}

A determinação da retenção de água em argamassas tem por função evitar que, durante a aplicação da argamassa em superfícies absorventes, ocorra perda da água de amassamento, necessária à hidratação do cimento, o que influencia diretamente no tempo disponível para aplicação, regularização e desempenho, e afeta algumas propriedades no estado endurecido, ao influenciar as reações dos aglomerantes durante a cura. Os resultados da retenção de água para as argamassas estão dispostos na Figura 4.

Foi realizada a análise ANOVA dos resultados obtidos para o valor-pdas argamassas, e para todas as propriedades analisadas esse índice foi menor que 0,05. Então, é válido afirmar que os valores médios das características das argamassas são diferentes entre si ao nível de 5\% de probabilidade, ou seja, pelo menos uma média é diferente entre si com um limite de confiança de $95 \%$.
Sendo assim, estatisticamente, o resultado da análise ANOVA mostrou que houve diferença significativa entre os quatroteores de substituição (5\%, 10\%, 15\% e $20 \%$ de substituição de areia por SCBA1) para todas as características analisadas.

Para saber quais médias são significativamente diferentes entre si, foi aplicado o teste de Tukey. As Tabelas 5 a 12 apresentam os valores médios das características para as argamassas produzidas com $5 \%, 10 \%, 15 \%$ e $20 \%$ de substituição parcial de areia por SCBA1, bem como o teste de Tukey, ao nível de $5 \%$ de probabilidade.

Através do tratamento estatístico é possível afirmar que não houve diferença significativa entre os valores médios da retenção de água da argamassa referência e os valores daquelas fabricadas com $5 \%$ a $15 \%$ de substituição parcial de areia por cinza pesada. Porém, a média da retenção de água com $20 \%$ de cinza mostrou-se superior e significativamente diferente das demais num limite de confiança de $95 \%$. Esses resultados indicam a possibilidade de utilização de até $15 \%$ de substituição parcial de cinza pesada por areia na produção de argamassas sem que haja alteração nessa característica.

A determinação da densidade de massa no estado fresco das argamassas se encontra na Figura 5.

Estatisticamente, é possível afirmar que houve diferença significativa entre os valores médios de densidade de massa da argamassa referência e os valores daquelas fabricadas com substituição parcial de areia por SCBA1. Essa diferença pode ter ocorrido em função do fato de a massa específica da SCBA1 ser maior do que a do agregado miúdo, ou até mesmo pelo fato de ter ocorrido melhora no empacotamento das partículas 
e refinamento dos poros pela substituição de grãos maiores por menores. Porém, os resultados mostram que, com relação à substituição parcial de areia por SCBA1, não há diferença significativa entre os valores médios da densidade de massa.

A determinação do teor de ar incorporado das argamassas está disposta na Figura 6.

Estatisticamente, houve diferença significativa entre os valores médios do teor de ar incorporado da argamassa referência e os valores daquelas fabricadas com substituição parcial de areia por SCBA1. Verifica-se, de forma análoga à característica de densidade de massa das argamassas, que para a substituição parcial de areia por SCBA1 não há diferença significativa entre os valores médios das argamassas produzidas com SCBA1 para essa propriedade. Os finos da SCBA1 provavelmente preencheram os poros da argamassa, pela substituição de grãos maiores por menores. Silva e Campiteli (2006) ressaltam que, à medida que aumenta o teor definos, diminui o teor de ar aprisionado nas argamassas. Para Silva e Campiteli (2006), o aumento doteor de finos aumenta a densidade demassa no estado fresco e também no estado endurecidodevido ao maior empacotamento provocado pelos finos. A maior densidade de massa e o menor teor de ar incorporado ocorrem na argamassa M2.

$\mathrm{Na}$ argamassa endurecida, o tamanho e a continuidade dos poros controlam a absorção de água e o coeficiente de capilaridade. A porosidade nas argamassas está relacionada à resistência mecânica de forma inversa (MEHTA; MONTEIRO, 2008). O coeficiente de capilaridade obtido para as argamassas pode ser observado na Figura 7.

Tabela 4 - Elementos químicos encontrados no extrato solubilizado de SCBA1 e de SCBA2 excedentes aos limites padrão da norma brasileira

\begin{tabular}{lccc}
\hline \multicolumn{1}{c}{ Componentes } & Limites (mg/l) & SCBA1 & SCBA2 \\
\hline Alumínio & 0,2 & 0,79 & 2,54 \\
Chumbo & 0,01 & 0,12 & 0,12 \\
Cádmio & 0,006 & 0,005 & 0,021 \\
Manganês & 0,1 & 0,02 & 0,29 \\
\hline
\end{tabular}

Figura 4 - Retenção de água das argamassas

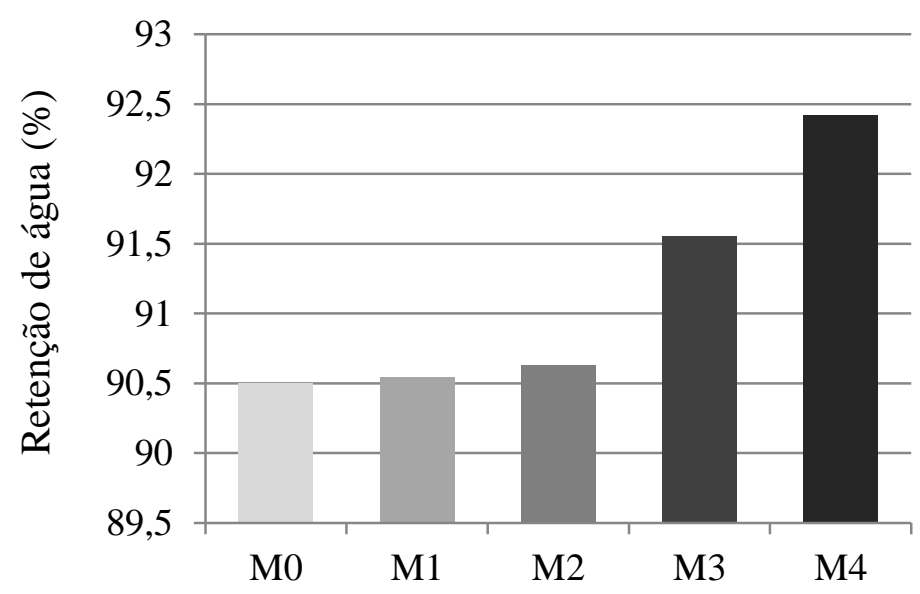

Formulação das argamassas 
Figura 5 - Densidade de massa das argamassas

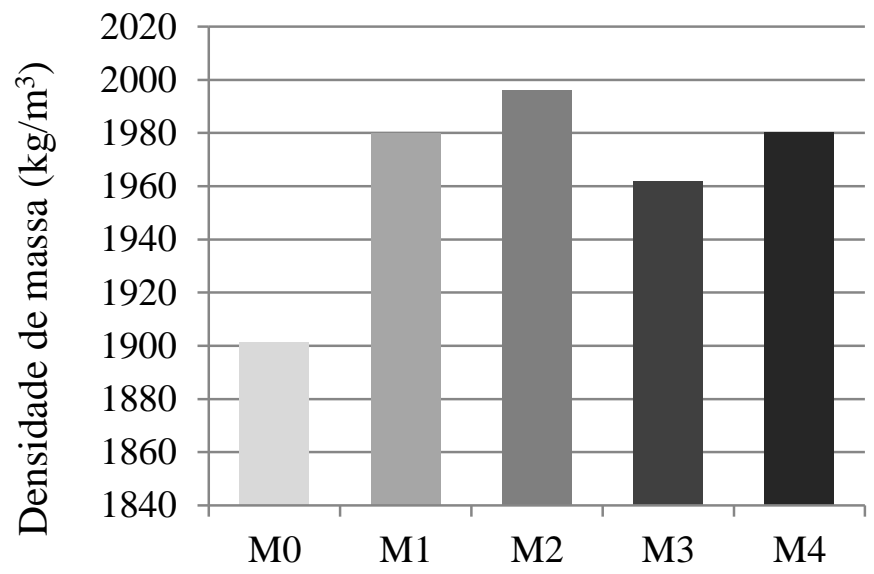

Formulação das argamassas

Figura 6 - Teor de ar incorporado das argamassas

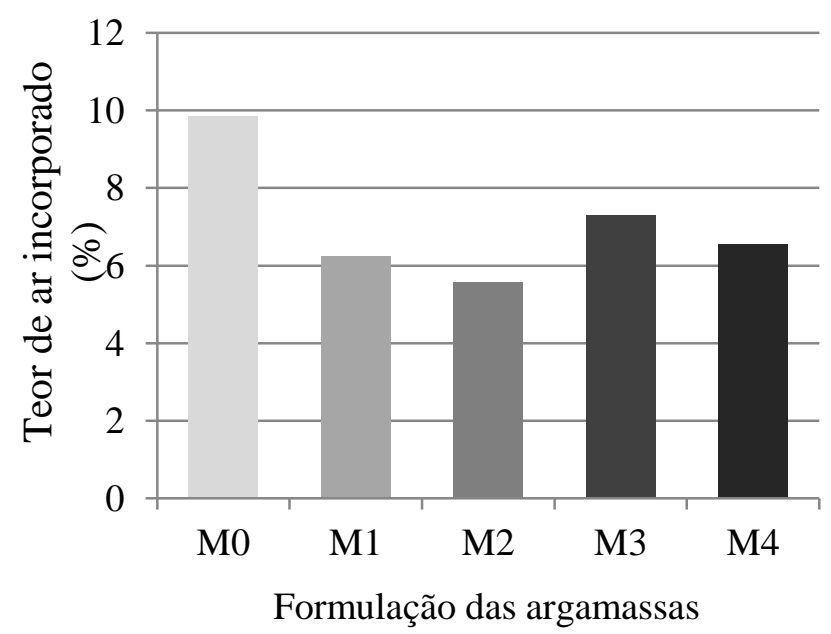

Figura 7 - Coeficiente de capilaridade das argamassas

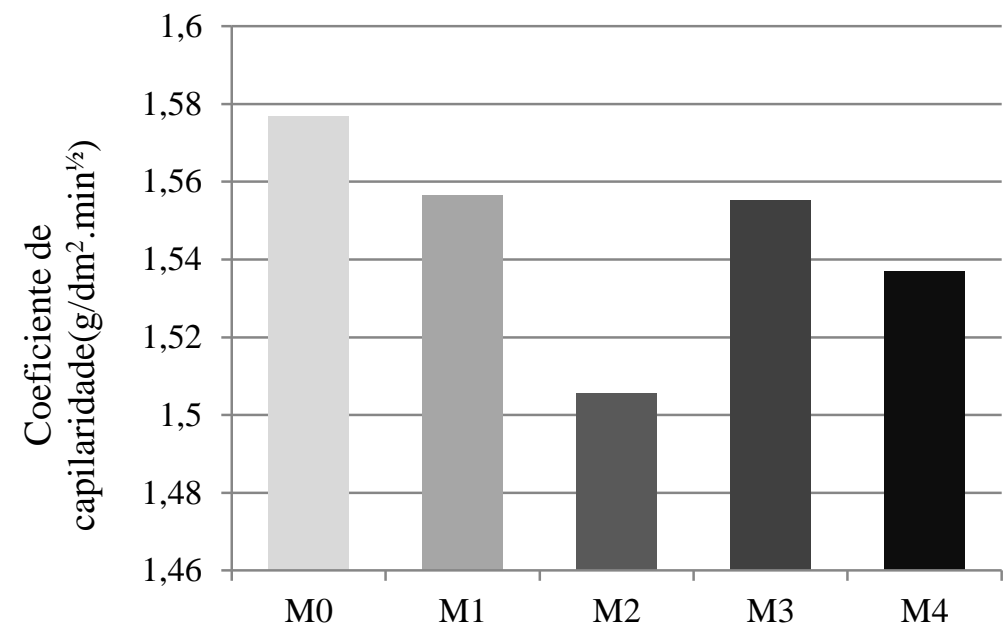

Formulação das argamassas 
Estatisticamente, é possível afirmar que não houve diferença significativa entre os valores médios do coeficiente de capilaridade da argamassa referência e os daquelas fabricadas com $5 \%, 15 \%$ e $20 \%$ de substituição parcial de areia por SCBA1. Verifica-se que o aumento do teor de substituição parcial de areia por cinza até $10 \%$ nas argamassas aumenta sua resistência mecânica à compressão axial.

A Norma 13279 (ABNT, 2005d) não comenta os valores máximos ou mínimos que os corpos de prova devem possuir em relação à tração na flexão ou à compressão axial. Os resultados podem ser vistos na Figura 8.

Não houve diferença significativa entre os valores médios de resistência à tração na flexão da argamassa referência e os valores daquelas fabricadas com $5 \%, 10 \%$ e $20 \%$ de substituição parcial de areia por SCBA1. Porém, a média da resistência à tração na flexão com $15 \%$ de cinza mostrou-se significativamente diferente das demais, inferior, num limite de confiança de $95 \%$. Esses resultados indicam a possibilidade de utilização de até $10 \%$ de substituição parcial de cinza pesada por areia na produção de argamassas sem alteração dessa propriedade. Para Bezerra et al. (2011), argamassas com resíduos apontam resistências superiores às do traço de referência, provavelmente pela diminuição da permeabilidade, devido ao processo de refinamento dos poros (efeito filler).
Estatisticamente não houve diferença significativa entre os valores médios da resistência à compressão axial da argamassa referência e os valores daquelas fabricadas com $5 \%, 15 \%$ e $20 \%$ de substituição parcial de areia por cinza pesada. Porém, verifica-se que o aumento do teor de substituição parcial de areia por cinza até $10 \%$ nas argamassas aumenta sua resistência mecânica à compressão. Esse fato ocorre porque o traço M2 apresentou anteriormente menor teor de ar incorporado e menor coeficiente de capilaridade (Figuras 6 e 7). Esse resultado justifica-se pelo fato de, segundo a NBR 13278 (ABNT, 2005c), o teor de ar incorporado ser a quantidade de ar presente em determinado volume de argamassa. Dessa forma, menor teor de ar incorporado leva ao aumento de sua resistência mecânica,sendo a porosidade nas argamassas relacionada à resistência mecânica de forma inversa (MEHTA; MONTEIRO, 2008). Descreve-se também que a SCBA1 pode ter realizado o preenchimento dos vazios das argamassas, denominado efeito filler, aumentando o empacotamento das partículas, e diminuído, consequentemente, os vazios, comprovado pela redução do coeficiente de capilaridade, o que favorece positivamente a resistência à compressão.

Os módulos de elasticidade longitudinal e flexional das argamassas se encontram na Figura 9.

Figura 8 - Resistência média das argamassas à tração na flexão e à compressão axial

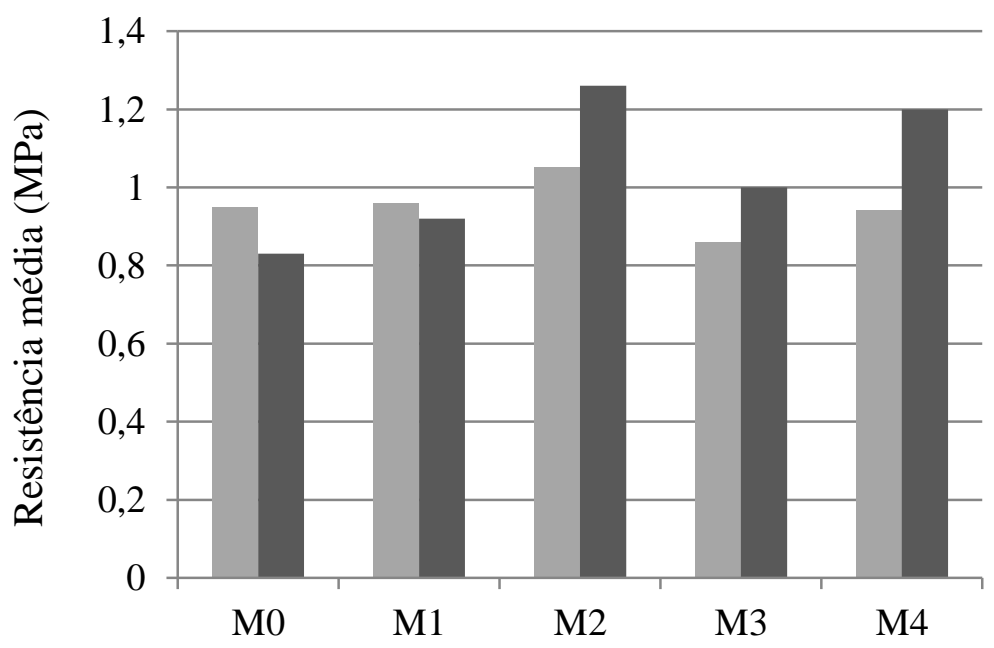

Formulação das argamassas

Resistência à tração na flexão $\quad$ Resistência à compressão axial 
Figura 9 - Módulo de elasticidade das argamassas

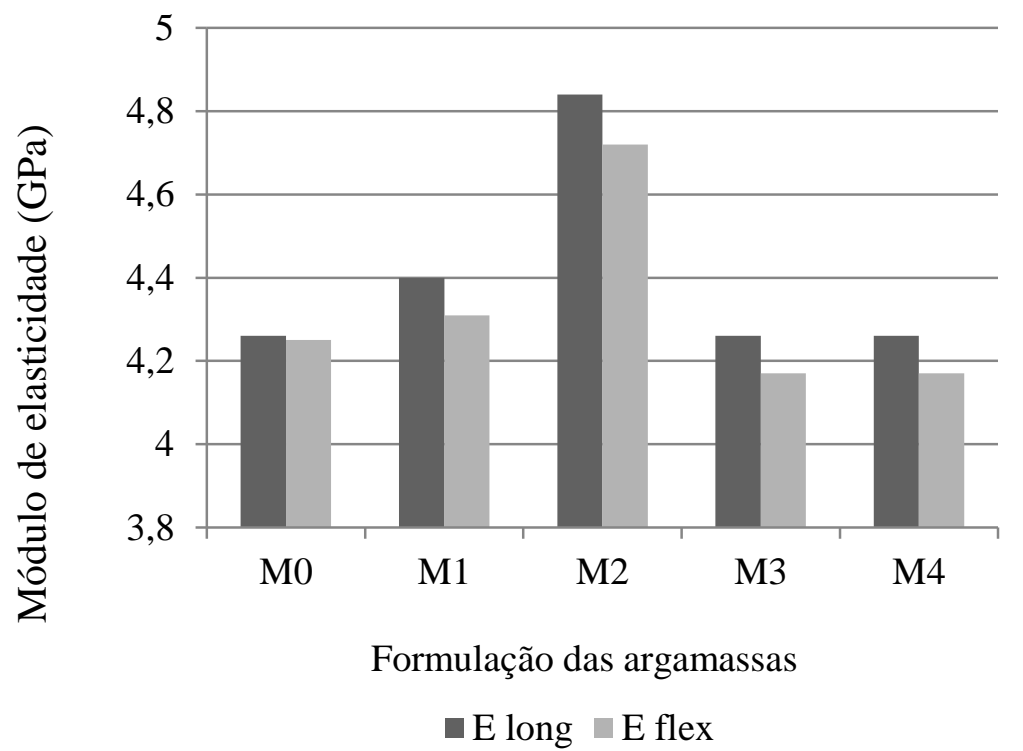

Assim como na propriedade anterior, é possível observar que não houve diferença significativa entre os valores médios do módulo de elasticidade longitudinal da argamassa referência e os valores daquelas fabricadas com $5 \%, 15 \%$ e $20 \%$ de substituição parcial de areia por SCBA1.Essa característica, no traço M2, está associada à característica do menor teor de ar incorporado, o que aumenta o módulo de elasticidade longitudinal da argamassa.

É possível afirmar estatisticamente que não houve diferença significativa entre os valores médios do módulo de elasticidade flexional da argamassa referência e os valores daquelas fabricadas com $5 \%, 15 \%$ e $20 \%$ de substituição parcial de areia por SCBA1. Novamente o teor de ar incorporado produz efeito análogo ao do módulo de elasticidade longitudinal.

Segundo Malhotra e Mehta (1996), o bom desempenho das resistências das argamassas M1 e M2, com $5 \%$ e $10 \%$ de substituição de areia pela SCBA1 respectivamente,pode ser justificado pelo fato de haver preenchimento dos vazios da argamassa, denominado efeito filler, quando há incorporação de resíduos, aumentando o empacotamento das partículas e diminuindo, consequentemente, os vazios, de forma a favorecer positivamente a resistência. Diante disso, a argamassa selecionada foi a M2, pois estatisticamente possui a mesma retenção de água, menor teor de ar incorporado, menor coeficiente de capilaridade e maior resistência à compressão axialque a argamassa de referência. Entretanto, destaca-se que as demais formulações também possuem características positivas e que a seleção de qualquer outra seria interessante para análise dareação dos dois tipos de cinzas numa mesma formulação de argamassa.

A nova argamassa produzida é denominada M2X, com a mesma formulação da argamassa M2, com $10 \%$ de substituição de agregado miúdo pela SCBA1, entretanto com a substituição de 7,5\% em massa de cimento pela SCBA2.

\section{Caracterização da argamassa mista (M2X) com adição de SCBA1 e SCBA2}

As Tabelas5 e 6 mostram a caracterização da argamassa M2X em comparação à M2 e ao traço de referência (M0), no estado fresco e no estado endurecido respectivamente. Foi possível observar quenão houve diferença significativa entre os traços com e sem a presença da SCBA2. Verificou-se aumento na resistência à compressão da M2 e da M2X em relação ao traço de referência (M0) devido à substituição de areia por SCBA1, porém entre os traços M2 e M2X não houve alteração nos valores de resistência mecânica, pois o teor de $7,5 \%$ de substituição em massa de cimento por SCBA2 não alterou essa propriedade, tendo em vista o índice de atividade pozolânica obtido no ensaio pela SCBA2 e conclusões obtidas no trabalho de Hojo (2014), apresentadas anteriormente. 
Tabela 5 - Comparação dos valores médios entre as propriedades no estado fresco das argamassas $M 2 X$, M2 e MO

\begin{tabular}{|c|c|c|c|c|}
\hline Séries & $\begin{array}{c}\text { Retenção de água } \\
(\%)\end{array}$ & $\begin{array}{l}\text { Densidade de massa } \\
\qquad\left(\mathrm{kg} / \mathrm{m}^{3}\right)\end{array}$ & $\begin{array}{c}\text { Teor de ar } \\
\text { incorporado }(\%)\end{array}$ & $\begin{array}{l}\text { Coeficiente de } \\
\text { capilaridade } \\
\left(\mathrm{g} / \mathrm{dm}^{2} . \mathrm{min}^{1 / 2}\right)\end{array}$ \\
\hline $\mathrm{M} 2 \mathrm{X}$ & 91,15 & 1.991 & 5,56 & 1,506 \\
\hline M2 & 90,63 & 1.996 & 5,58 & 1,505 \\
\hline M0 & 90,5 & 1.901 & 9,87 & 1,576 \\
\hline
\end{tabular}

Tabela 6 - Comparação dos valores médios entre as propriedades no estado endurecido das argamassas $M 2 X, M 2$ e $M 0$

\begin{tabular}{lcccc}
\hline \multirow{2}{*}{ Séries } & \multicolumn{2}{c}{ Resistência média(MPa) } & \multicolumn{2}{c}{ Módulo de elasticidade (GPa) } \\
\cline { 2 - 5 } & $\begin{array}{c}\text { Resistência à } \\
\text { tração na flexão }\end{array}$ & $\begin{array}{c}\text { Resistência à compressão } \\
\text { axial }\end{array}$ & E long & E flex \\
\hline M2X & 1 & 1,25 & 4,25 & 4,29 \\
M2 & 1,05 & 1,26 & 4,33 & 4,47 \\
M0 & 0,95 & 0,83 & 4,26 & 4,25 \\
\hline
\end{tabular}

\section{Conclusões e recomendações}

A utilização de cinzas do bagaço de cana-deaçúcar para a produção de argamassas parece ser uma interessante forma de aproveitamento desse resíduo, podendo reduzir a necessidade de áreas para destiná-lo e, ao mesmo tempo, utilizando menos areia e cimento, o que diminui o impacto ambiental da extração desses materiais.

A substituição parcial de agregado miúdo por SCBA1 provocou diminuição da trabalhabilidade das argamassas, porém isso foi corrigido com a utilização de superplastificante. Entretanto, a adição do superplastificante pode ser desvantajosa, já que a cal, entre várias outras funções, também é utilizada para essa finalidade, e o uso de mais um material gera custos.

Com relação à substituição de areia por SCBA1, a argamassa com o teor ideal desse resíduo foi a M2, $10 \%$ de substituição de areia por SCBA1, pois estatisticamente possui a mesma retenção de água que a argamassa de referência, possui menor teor de ar incorporado, menor coeficiente de capilaridade e maior resistência à compressão axial. Entretanto, destaca-se que, embora neste trabalho se tenha optado por $10 \%$ de areia por SCBA1, as demais formulações também possuem características positivas e que a seleção de qualquer outra seria interessante para análise da reação dos dois tipos de cinzas numa mesma formulação.

A substituição parcial de $7,5 \%$ do cimento pela SCBA2 não trouxe variabilidade significativa para as argamassas, o que pode ser considerado positivo, porque a adição do resíduo não afetou negativamente o traço. Isso está relacionado ao fato de a SCBA2 possuir atividade pozolânica. Hojo (2014) mostrou que esse teor de substituição parcial de cimento para essa cinza não alterou as características do produto produzido.

Ao longo de uma única pesquisa não é possível analisar todas as distintas possibilidades que um novo material pode oferecer. Outras variáveis devem ser estudadas em outras pesquisas no que se refere à substituição de cinzas em argamassas. Por isso, sugerem-se como trabalhos futuros:

(a) desenvolver estudos para os traços de argamassas mistas utilizados sem a adição de superplastificante, a fim de verificar o comportamento alcançado pelos traços M3 e M4;

(b) com o objetivo de obter um teor de substituição maior de agregado miúdo por cinza pesada, avaliar as propriedades de um traço de argamassa com teor de substituição de $20 \%$ de areia por cinza pesada e de $7,5 \%$ de substituição de cimento por cinza leve, pois se verificou no trabalho que o teor de substituição de $20 \%$ de SCBA1 não alterou negativamente as propriedades da argamassa em relação à referência;

(c) desenvolver estudos mais aprofundados para o traço M2X, variando substituições de SCBA2 por cimento e utilizando-se aditivos; e

(d) aplicar a argamassa confeccionada em painéis para testes de aderência (arrancamento) de revestimentos - fazer a aplicação de ensaios neles, a fim de correlacionar seus resultados com os ensaios já realizados.

148 Castro, T. R. de; Martins, C. H. 


\section{Referências}

AGREDO, J. T. et al.Characterizationof Sugar Cane Bagasse Ash as Supplementary Material For Portland Cement. Ingeniería e Investigación, v. 34, n. 1, p. 5-10, 2014.

AKRAM, T.; MEMON, S. A.; OBAID, H. Production of Low Cost Self Compacting Concrete Using Bagasse Ash. Construction and Building Materials, v. 23, n. 2, p. 703-712, 2009.

ALWAELI, M. Application of Granulated LeadZinc Slag in Concrete as an Opportunity to Save Natural Resources. Radiation Physics and Chemistry, v. 83, p. 54-60, 2013.

AMERICAN SOCIETY FOR TESTING AND MATERIALS. ASTM E1876-09: standard test method for dynamic young's modulus, shear modulus, and poisson's ratio by impulse excitation of vibration. Pensilvânia, 2012.

ASSOCIAÇÃO BRASILEIRA DE NORMAS TÉCNICAS. NBR 6502: rochas e solo. Rio de Janeiro, 1995.

ASSOCIAÇÃO BRASILEIRA DE NORMAS TÉCNICAS. NBR 6508:massa específica dos sólidos. Rio de Janeiro, 1984a.

ASSOCIAÇÃO BRASILEIRA DE NORMAS

TÉCNICAS. NBR 7181: solo: análise granulométrica. Rio de Janeiro, 1984b.

ASSOCIAÇÃO BRASILEIRA DE NORMAS TÉCNICAS. NBR 7215: cimento Portland: determinação da resistência à compressão. Rio de Janeiro, 1996.

ASSOCIAÇÃO BRASILEIRA DE NORMAS TÉCNICAS. NBR 10004: resíduos sólidos: classificação. Rio de Janeiro, 2004a.

ASSOCIAÇÃO BRASILEIRA DE NORMAS TÉCNICAS. NBR 10005: procedimento para obtenção de extrato lixiviado de resíduos sólidos. Rio de Janeiro, 2004b.

ASSOCIAÇÃO BRASILEIRA DE NORMAS TÉCNICAS. NBR 10006: procedimento para obtenção de extrato solubilizado de resíduos sólidos. Rio de Janeiro, 2004c.

ASSOCIAÇÃO BRASILEIRA DE NORMAS TÉCNICAS. NBR 13276: argamassa para assentamento e revestimento de paredes e tetos: preparo da mistura e determinação do índice de consistência. Rio de Janeiro, 2005a.

ASSOCIAÇÃO BRASILEIRA DE NORMAS TÉCNICAS. NBR 13277: argamassa para assentamento e revestimento de paredes e tetos: determinação da retenção de água. Rio de Janeiro, $2005 b$.
ASSOCIAÇÃO BRASILEIRA DE NORMAS

TÉCNICAS. NBR 13278: argamassa para assentamento e revestimento de paredes e tetos: determinação da densidade de massa e do teor de ar incorporado. Rio de Janeiro, 2005c.

ASSOCIAÇÃO BRASILEIRA DE NORMAS TÉCNICAS. NBR 13279: argamassa para assentamento e revestimento de paredes e tetos: determinação da resistência à tração na flexão e à compressão. Rio de Janeiro, 2005d.

\section{ASSOCIAÇÃO BRASILEIRA DE NORMAS} TÉCNICAS. NBR 15259: argamassa para assentamento e revestimento de paredes e tetos: determinação da absorção de água por capilaridade e do coeficiente de capilaridade. Rio de Janeiro, 2005e.

\section{ASSOCIAÇÃO BRASILEIRA DE NORMAS}

TÉCNICAS. NBR 15895: materiais pozolânicos: determinação do teor de hidróxido de cálcio fixado: método Chapelle modificado. Rio de Janeiro, 2010.

\section{ASSOCIAÇÃO BRASILEIRA DE NORMAS}

TÉCNICAS. NBR NM 24: materiais pozolânicos: determinação do teor de umidade. Rio de Janeiro, 2003.

ASSOCIAÇÃO BRASILEIRA DE NORMAS TÉCNICAS. NBR NM 18: cimento Portland: análise química: determinação de perda ao fogo. Rio de Janeiro, 2012.

BEZERRA, I. M. T. et al.Aplicação da Cinza da Casca do Arroz em Argamassas de Assentamento. Revista Brasileira de Engenharia Agrícola Ambiental, v. 15, n. 6, p. 639-645, 2011.

BRITO, A. L. F. Protocolo de Avaliação de Materiais Resultantes da Estabilização Por Solidificação de Resíduos. Florianópolis, 2007. Tese (Doutorado em Engenharia Civil) -Escola de Engenharia, Universidade Federal de Santa Catarina, Florianópolis, 2007.

BROWN, S.; LUGO, A. E. Rehabilitation of Tropical Lands: a key to sustaining developing. Restoration Ecology, v. 2, n. 2, p. 97-111, 1994.

CHEN, C. et al. The Effects of the MechanicalChemical Stabilization Process for Municipal Solid Waste Incinerator Fly Ash on the Chemical Reactions in Cement Paste. Waste Management, v. 33, p. 858-865, 2013. 
COMPANHIA NACIONAL DE

ABASTECIMENTO. Acompanhamento da

Safra Brasileira de Cana-de-Açúcar

2013/2014:segundo levantamento. 2013.

Disponível em:

<http://www.conab.gov.br/OlalaCMS/uploads/arq uivos/13_08_08_09_39_29_boletim_cana_portugu es_-abril_2013_1o_lev.pdf $>$. Acesso em: $16 \mathrm{fev}$. 2015.

CORDEIRO, G. C. et al.Ultrafine Grinding of Sugar Cane Bagasse Ash for Application as Pozzolanic Admixture in Concrete. Cement and Concrete Research, v. 39, n. 2, p. 110-115, 2009.

FARAONE, N. et al. Steelmaking Slag as Aggregate for Mortars: effects of particle dimension on compression strength. Chemosphere, v. 77, n. 8, p. 1152-1156, 2009.

FARIA, K. C. P.; GURGEL, R. F.; HOLANDA, J. N. F. Recycling of Sugarcane Bagasse Ash Waste in the Production of Clay Bricks. Journal of Environmental Management, v. 101, p. 7-12, 2012.

FRÍAS, M.; VILLAR, E.; SAVASTANO, H. Brazilian Sugar Cane Bagasse Ashes From the Cogeneration Industry as Active Pozzolans for Cement Manufacture. Cement \& Concrete Composites, v. 33, n. 4, p. 490-496, 2011.

GONZÁLEZ-LÓPEZ, J. R. et al.Small Addition Effect of Agave Biomass Ashes in Cement Mortars. Fuel Processing Technology, v. 133, p. 35-42, 2015.

HOJO, L. Y. C. P. Análise da Atividade Pozolânica da Cinza Volante do Bagaço de Cana-de-Açúcar Para Substituição Parcial do Cimento Portland. Maringá, 2014.Dissertação (Mestrado em Engenharia Civil) - Escola de Engenharia, Universidade Estadual de Maringá, Maringá, 2014.

IBRAHIM, A. R. B. et al.Analyzing the Dynamics of the Global Construction Industry: past, present and future. Benchmarking: an International Journal, v. 17, n. 2, p. 232-252, 2010.

LIMA, S. A. et al. Analysis of the Mechanical Properties of Compressed Earth Block Masonry Using the Sugarcane Bagasse Ash.
ConstructionandBuildingMaterials, v. 35, p.829-837, oct. 2012.

MACEDO, P. C. Avaliação do Desempenho de Argamassas Com Adição de Cinza do Bagaço de Cana-de-Açúcar. Ilha Solteira,2009. 113 f. Dissertação (Mestrado em Engenharia Civil) Faculdade de Engenharia, Departamento de Engenharia Civil, Universidade Estadual Paulista, Ilha Solteira, 2009.

MALHOTRA, V. M.; MEHTA, P. K. Pozzolanic and Cementitious Materials. Amsterdam: Advances in Concrete Technology, 1996.

MEHTA, P. K.; MONTEIRO, P. J. M. Concreto: microestrutura, propriedades e materiais. 3. ed. São Paulo: Arte Interativa, 2008.

MONTGOMERY, D. C.; RUNGER, G. C. Estatística Aplicada e Probabilidade Para Engenheiros. 5. ed. Rio de Janeiro: LTC, 2013.

SALES, A.; LIMA, S. A. Use of Brazilian Sugarcane Bagasse Ash in Concrete as Sand Replacement. Waste Management, v. 30, n. 6, p. 1114-1122, 2010.

SILVA, N. G. da; CAMPITELI, V. C. Influência dos Dinos de Cal nas Propriedades das Argamassas. In: ENCONTRO NACIONAL DE TECNOLOGIA NO AMBIENTE CONSTRUÍDO, 11., Florianópolis, 2006. Anais... Florianópolis, 2006.

SOUZA, A. E. et al. Reuse of Sugar Cane Bagasse Ash (SCBA) to Produce Ceramic Materials.

Journal of Environmental Management, v. 92, n. 10, p. 2774-2780, 2011.

UYGUNOGLU, T. et al. The Effect of Fly Ash Content and Types of Aggregates on the Properties of Pre-Fabricated Concrete Interlocking Blocks (PCIBs). Construction and Building Materials, v. 30, p. 180-187, 2012.

\section{Agradecimentos}

À Coordenação de Aperfeiçoamento de Pessoal e Nível Superior (Capes) e à Fundação Araucária de Apoio ao Desenvolvimento Científico e Tecnológico do Paraná, pelos recursos disponibilizados. 


\section{Tainara Rigotti de Castro}

Departamento de Engenharia de Produção Agroindustrial | Universidade Estadual do Paraná | Av. Comendador Norberto Marcondes, 733, Centro | Campo Mourão - PR - Brasil | CEP 87303-100 | Tel.: (44) 3518-1880 | E-mail: tainararcastro@hotmail.com

Carlos Humberto Martins

Departamento de Engenharia Civil | Universidade Estadual de Maringá | Av. Colombo, 5790 Centro Universitário | Maringa - PR - Brasil | CEP 87020-900 | Tel.: (44) 3011-4322 Ramal 1338 | E-mail: chmartins@uem.br

\section{Revista Ambiente Construído}

Associação Nacional de Tecnologia do Ambiente Construído

Av. Osvaldo Aranha, $99-3^{\circ}$ andar, Centro

Porto Alegre - RS - Brasil

CEP 90035-190

Telefone: +55 (51) 3308-4084

Fax: +55 (51) 3308-4054

www.seer.ufrgs.br/ambienteconstruido

E-mail: ambienteconstruido@ufrgs.br 